\section{Pneumonia and hospitalizations in the elderly}

Francesco Cacciatore, ${ }^{1,2}$ Carlo Gaudiosi, ${ }^{3}$ Francesca Mazzella, ${ }^{4}$

Anna Scognamiglio, ${ }^{1}$ Irene Mattucci, ${ }^{2}$

Mauro Carone, ${ }^{3}$ Nicola Ferrara, ${ }^{5}$

Pasquale Abete $^{5}$

${ }^{1}$ Cardiac Rehabilitation, Maugeri

Foundation, Institute of Rehabilitation

of Telese Terme (BN); ${ }^{2}$ Unit of

Cardiosurgery and Transplntation,

Monaldi Hospital, Napoli;

${ }^{3}$ Pneumological Rehabilitation, Maugeri

Foundation, Institute of Rehabilitation

of Telese Terme (BN); ${ }^{4}$ Emergency

Department, Cardarelli Hospital,

Napoli; ${ }^{5}$ Department of Translational

Medical Sciences, Federico II University, Napoli, Italy

\section{Abstract \\ Pneumonia in the elderly is a common and severe problem. In this review we ana- lyze the state of the art for pneumonia in the elderly. Several aspects are discussed: i) how common is the disease; signs and symptoms in the elderly; ii) the elderly must always be hospitalized and which is the best place - Intensive Care Unit or medical ward?; iii) the role of comorbidi- ties; iv) etiology and pathogenesis; med- ical treatment - when and how to start; v) antibiotic resistance; vi) antibiotics in hos- pital acquired and ventilator related pneu- monia; vii) assisted non-invasive ventila- tion; viii) the treatment in the terminally ill elderly patient.}

\section{Definition}

William Osler, known as the father of modern medicine, in 1918 considering the severity and disability caused by pneumonia, described it as the "the old man's friend, where death is often quick and painless". Pneumonia is an infection of the lung tissue. When a person has pneumonia, the air sacs in his/her lungs become filled with microorganisms, fluid, and inflammatory cells and his/her lungs are not able to work properly. Diagnosis of pneumonia is based on symptoms and signs of an acute lower respiratory tract infection and can be confirmed by a chest X-ray showing new shadowing that is not due to any other cause (such as pulmonary edema or infarction). ${ }^{2}$

\section{Epidemiology}

Pneumonia is a frequent illness highly conditioning morbidity and mortality in the elderly population. In this age group, similarly, in all racial group, it is the fourth leading cause of death and the leading cause of death from infectious disease. ${ }^{3}$ Pneumonia often is the terminal event that complicates a long-term illness (dementia, cancer, as prolonged immobilization syndrome). We distinguish different types of pneumonia depending on the environment in which they develop: community acquired pneumonia (CAP) or pneumonia community, nursing home acquired pneumonia (NHAP) or hospital acquired pneumonia (HAP) or in hospital development and ventilator-associated pneumonia (VAP).

The incidence of CAP is $25-44$ cases per $1000,{ }^{4}$ reaching 52 cases per 1000 for those aged 85 years or older. ${ }^{5}$ Data derived from an observational study conducted by our group in the Emergency Department of Cardarelli Hospital in Naples, between 1 January 2015 and 15 October 2015, identified 3255 patients with respiratory infection diagnosis [diagnosis-related group (DRG) 486-4809 - 4829-4660 - 49121-49122] on 72134 accesses to the Emergency Department. The incident rate of respiratory infection is $45 / 1000$ patients of which $1559 / 72134$ corresponding to an incidence rate of 22/1000 with a diagnosis of pneumonia, increasing to $77.4 / 1000$ for patients with 65 years and over. In elderly patients hospitalized for pneumonia, the mortality rate is about $20 \%{ }^{6}$ If pneumonia develops in patients already hospitalized for other conditions, mortality increase to $50-70 \%$, and is higher in women than in men. ${ }^{6}$ Pneumonia is the most common form of hospital-acquired infection. Data from European Center Disease Control (ECDC), published in 2015, related to a survey conducted on 231,459 patients hospitalized between 2011 and 2012, identified 13829 patients $(6.0 \%)$ with hospital infection. ${ }^{7}$ The most common infectious are pneumonia and infection of the lower respiratory tract ( $19.4 \%$ and $4.1 \%$, respectively). ${ }^{7}$ Relevant incidence rates are also observed in longterm care facilities where 100-250 of 1000 patients develop pneumonia. ${ }^{8}$

\section{Symptoms, signs, and diagnosis in the elderly}

The typical clinical features of pneumonia (fever, cough and sputum production) are often unclear and not fully manifest in elder-
Correspondence: Francesco Cacciatore, Unit of Cardiosurgery and Transplntation, Monaldi Hospital, Napoli, Italy.

E-mail: francesco.cacciatore@fsm.it

Key words: Pneumonia; elderly; hospitalization.

Contributions: FM, AS, data collecting and analyzing; FC, CG, IM, PA manuscript writing; MC, NF, manuscript reviewing, FC, FM, AS, CG, IM references search.

Received for publication: 8 November 2016 . Revision received: 21 April 2017.

Accepted for publication: 21 April 2017.

This work is licensed under a Creative Commons Attribution-NonCommercial 4.0 International License (CC BY-NC 4.0).

CCopyright F. Cacciatore et al., 2017

Licensee PAGEPress, Italy

Geriatric Care 2017; 3:6377

doi: $10.4081 /$ gc. 2017.6377

ly patients. Only in 33-60\% of elderly patients, the disease begins with a high fever. ${ }^{9}$ Common signs and symptoms in elderly are: falls, sudden change in functional status, decreased appetite, urinary incontinence, delirium / acute confusional state, frequent but less common signs are: pleuritic chest pain, cough, dyspnea, fever, and leukocytosis. ${ }^{10}$ (Figure 1). The chest x-ray usually consents to make the diagnosis but does not provide information on the etiology. In Nursing Home, the predictive power of radiology is extremely low. Among 2334 episodes of pneumonia in 1474 nursing home residents, $45 \%$ of the radiograph reports suggested disease (possible $=12 \%$; probable or definite $=33 \%$ ). ${ }^{11}$ In the elderly patient, the atypical presentation is often the rule, and the diagnosis does not follow the typical adult's path because the presence of co-morbidities and anergy of the immune system makes presentation completely different. ${ }^{12}$ The assessment of oxygen-hemoglobin saturation by pulse oximetry may be useful in nursing home residents, in whom values below $94 \%$ accompanied by signs of infection were predictive of pneumonia with a sensitivity of $80 \%$ and specificity of $91 \%{ }^{13}$ The multidimensional assessment with a focus on cognitive status and changes in physical function may drive to the recognition of pneumonia, which frequently manifests with delirium. ${ }^{14}$ The most important imaging tool is conventional chest radiography. The role of radiography is to detect or rule out infiltrates, to show the extent of disease and possible complications, and to show a response to treatment. ${ }^{15}$ If pneumonia is 
suspected in an immunocompromized patient, a negative chest radiography (CR) is not adequate to rule out infection, and a computed tomography (CT) should be done. Complications like empyema or abscesses are shown superiorly by CT. ${ }^{15}$

In the last years, the use of lung ultrasound (LUS) in the evaluation of pneumonia is growing rapidly. Although many traditional imaging applications are still indicated and will be used indefinitely for patients with possible pneumonia, lung ultrasound can substantially decrease the practical delays associated with plain chest radiography and in some cases can obviate the need for chest CT when a definitive diagnosis is obtained on ultrasound imaging, avoiding a large radiation dose. In many cases when pneumonia is in the differential diagnosis, lung ultrasound should come first. ${ }^{16}$ These aspects make LUS an easy tool to apply to frail patients that are bedridden and in settings such as long-term care and Nursing Home where CT scan is not available. LUS could be helpful in iden- tifying pneumonia in a complex elderly patient in the community and ICU (ventilated). A recent meta-analysis established the accuracy of LUS and CR for the diagnosis of adult CAP, considering chest CT scan as a gold standard. LUS had a pooled sensitivity of 0.95 and a specificity of 0.90 , while CR had a pooled sensitivity of 0.77 and a specificity of 0.91 . The areas under the curve for LUS and CR were 0.901 and 0.590 , respectively, indicating that LUS can help to diagnosis adult CAP. ${ }^{17}$

\section{Comorbidity and pneumonia in the elderly}

Highly prevalent conditions such as disability, frailty, and comorbidities are associated with an increased risk of pneumonia and a higher mortality rate. Comorbidity was present in $46.6 \%$ of younger patients, while it is highly prevalent $(88.2 \%)$ in the elderly, strongly affect-

\begin{tabular}{|l|l|}
\hline \multicolumn{1}{|c|}{ Elderly } & \multicolumn{1}{c|}{ Adult } \\
\hline Fever $80 \%$ & History of cough, \\
Tachypnea (RR >24) & fever, or dyspnea 44\% \\
$45-70 \%$ & Change in mental \\
Pleuritic chest pain, & status/confusion 33- \\
cough productive of & $66 \%$ \\
purulent sputum $80 \%$ & Tachypnea (RR $>30)$ \\
Chills $40-50 \%$ & $26-75 \%$ \\
Chest pain $30 \%$ & Tachycardia 10-15\% \\
& Recent falls $10 \%$ \\
\hline
\end{tabular}

Figure 1. Symptoms and signs in elderly and adults. ing mortality $3.7 \%$ in younger patients with comorbidity vs. $20.7 \%$ of older patients with comorbidity) (Table 1). ${ }^{18}$ The known risk factors for pneumonia are age, asthma, immunosuppression, heart disease and institutionalization. The most significant predictors of mortality, at least in CAP, are kidney failure, increased respiratory rate of 30 breaths/min, and a diastolic blood pressure less than $60 \mathrm{mmHg}$, all these conditions are common in elderly especially in frail patients hospitalized for heart failure, cancer, and hip fracture. ${ }^{19}$ The American Thoracic Society (ATS) published guidelines for the management of both CAP and HAP. These guidelines suggest specific assessment pathways, treatment, and rehabilitation of patients with pneumonia by specific risk factors, age, and place of treatment.

\section{Diagnostic and prognostic score to assess severity and the appropriate setting of care}

The elderly patient present with some clinical problems that must be considered when deciding the optimal setting of care: delirium, hypoxic respiratory failure, and severe sepsis. Assessment of disease severity can help to determine the optimal setting of care. Pneumonia severity index (PSI) ${ }^{20,21}$ and the CURB-65 score (an acronym for confusion, blood urea nitrogen, respiratory rate, systolic blood pressure or diastolic blood pressure, and age $>65$ ) are the most widely studied scores evaluating patients with CAP. ${ }^{22}$

Even if these scores are useful in the adult population, demonstrating its effectiveness and safety in increasing the proportion of low-risk patients who can receive treatment in the outpatient setting, ${ }^{21}$ in geriatric patients hospitalized with aspiration pneumonia, CURB-65 and PSI have no prognostic value. ${ }^{23}$ Moreover, it has been

Table 1. Overall outcome in young and elderly hospitalized patients: effect of comorbidity.

\begin{tabular}{|c|c|c|c|}
\hline \multirow[t]{2}{*}{ Variable } & \multicolumn{2}{|c|}{ Age } & \multirow[t]{2}{*}{ P value } \\
\hline & $<65$ years $(\mathrm{N}=4083)$ & $\geq 65$ years $(\mathrm{N}=3720)$ & \\
\hline $\begin{array}{l}\text { Hospitalized } \\
30 \text { days mortality } \\
180 \text { days mortality }\end{array}$ & $\begin{array}{c}64(3.0) \\
114(5.4)\end{array}$ & $\begin{array}{c}278(9.2) \\
528(18.8)\end{array}$ & $\begin{array}{l}0.001 \\
0.001\end{array}$ \\
\hline $\begin{array}{l}\text { With comorbidity } \\
30 \text { days mortality } \\
180 \text { days mortality }\end{array}$ & $\begin{array}{l}58(1.4) \\
93(2.3)\end{array}$ & $\begin{array}{c}268(7.2) \\
503(13.5)\end{array}$ & $\begin{array}{l}0.001 \\
0.001\end{array}$ \\
\hline Overall 151 & $(3.7)$ & $771(20.7)$ & 0.001 \\
\hline
\end{tabular}

Modified from Klapdor et al., 2012.18 
demonstrated that they are rarely used by physicians in clinical practice, mainly because of a large number of variables needed to calculate each score. ${ }^{24}$ Therefore, an accurate assessment of the appropriate site of care for elderly patients cannot rely only on the assessment scores and other factors should be considered. ${ }^{25}$ The Infectious Diseases Society of America (IDSA)/ATS of $2007^{26}$ guidelines recommend, to decide the correct site of care, the determination of subjective factors, including the ability to safely and reliably take oral medication and the availability of outpatient support resources (Strong recommendation; level II evidence). In elderly patients with complex clinical conditions, the process of cure should take in account comorbidities and social factors, such as homelessness. Previous studies demonstrated that no scoring system could replace clinical decision on the correct site of care. ${ }^{27}$ Prospective studies have shown that physicians still admit at least $30-60 \%$ of low mortality risk patients when using the PSI to guide the appropriate site of care. These prognostic tools are imperfect in the elderly, and their failure to include certain comorbidities [chronic obstructive pulmonary disease (COPD), immune suppression] and social factors makes these evaluation un-useful for complex elderly patients. ${ }^{27}$ Recently, geriatric approach to defining the appropriate site of care is based on presence of frailty, a typical geriatric condition that strongly affects mortality especially in elderly with respiratory diseases. ${ }^{28}$ To confirm these findings, recent studies of older patients hospitalized for CAP demonstrated that the multidimensional prognostic index (MPI), a validated prognostic tool based on information on functional and cognitive status, nutrition, mobility, comorbidity, polypharmacy and co-habitation status collected through a comprehensive geriatric assessment (CGA), was significantly more effective in this high-risk population to predict short- and long-term mortality than $\mathrm{PSI}^{29}$ and procalcitonin serum levels ${ }^{30}$ with excellent calibration and very good accuracy (area under the receiver operating characteristic [ROC] curve $=0.83$ at 30 days and 0.80 after one year of follow-up).

The 2007 Guidelines form IDSA, identified criteria for ICU admission for CAP, that is the presence of one of two major criteria: invasive mechanical ventilation required and septic shock with the need of vasopressors or at least the presence of 3 minor criteria: confusion/disorientation, blood urea nitrogen $\geq 20 \mathrm{mg} \%$, Respiratory rate $\geq 30 / \mathrm{min}$; core temperature $<36^{\circ} \mathrm{C}$, Severe hypotension; ratio of partial pressure of arterial $\mathrm{O}_{2}$ to the fraction of inspired $\mathrm{O}_{2}$
$\left(\mathrm{PaO}_{2} / \mathrm{FiO}_{2}\right.$ ratio $) \leq 250$, multi-lobar infiltrates, white blood cells $<4000$ cells; platelets $<100,000 .^{26}$

\section{Etiology}

In $95 \%$ of outpatient cases and $50 \%$ of hospitalized cases, the etiologic agent was not recognized. Often the agent isolated is not necessarily responsible for the infection. The previous antibiotic therapy may mislead the bacteriological examination results. Frequently the etiological diagnosis is retrospective serum colonization of the airways by potentially pathogenic bacteria. Gram and gram + occurs most often in the elderly than in younger people, which is partly due to factors such as repeated antibiotic therapies, endotracheal intubation, COPD, malnutrition and coexisting comorbidities. ${ }^{31}$

Some pathogens can give rise to CAP, generally categorized into typical and atypical pathogens. ${ }^{26}$

Typical bacterial pathogens that cause CAP include Streptococcus pneumonia (penicillin-sensitive/resistant strains), Haemophilus influenza (ampicillin-sensitive/resistant strains), and Moraxella catarrhalis (all strains penicillin-resistant) and account for approximately $85 \%$ of CAP cases. ${ }^{26} S$. pneumonia (which causes pneumococcal pneumonia) is the most frequent bacterial causative agent of communityacquired pneumonia in the elderly. It is responsible for $15-50 \%$ of all pneumonia of adults diagnosed by culture. It is estimated that the attack rate of pneumococcal pneumonia is of 46/1000 in people aged $>65$ years. Patients $>65$ years have a risk 3 to 5 times higher of dying from this type of pneumonia, compared to young people. ${ }^{32}$

CAP is usually acquired via inhalation or aspiration of a pulmonary pathogen into a lung segment or lobe. Less commonly, CAP results from secondary bacteremia from a distant source, such as Escherichia coli urinary tract infection and bacteremia. Aspiration pneumonia is the only form of CAP caused by multiple pathogens (e.g., aerobic/anaerobic oral organisms). Klebsiella pneumonia CAP occurs primarily in persons with chronic alcoholism and Staphylococcus aureus may cause CAP in patients with influenza. Pseudomonas aeruginosa is a cause of CAP in patients with bronchiectasis or cystic fibrosis. ${ }^{26}$

Atypical pathogen CAP manifests a variety of pulmonary and extrapulmonary findings (e.g., CAP plus diarrhea). Atypical CAP can be divided into those caused by either zoonotic or non-zoonotic atypical pathogens. Zoonotic atypical CAP pathogens include Chlamydia psittaci (psittacosis), Coxiella burnetii (Q fever), and Francisella tularensis (tularemia). Nonzoonotic atypical CAP pathogens include Mycoplasma pneumoniae, Legionella species, and Chlamydia pneumoniae. These organisms account for approximately $15 \%$ of all CAP cases. ${ }^{26}$ For all suspected CAP patients, in light of better outcomes with the earliest possible interventions IDSA recommends initial empiric antimicrobial therapy until laboratory results can be obtained to guide more specific therapy. ${ }^{26}$

Methicillin-resistant S. aureus (MRSA) is among the most frequently identified pathogens causing healthcare-associated pneumonia (HCAP), HAP, and VAP worldwide. ${ }^{33}$ Although it appears to be a relatively uncommon cause of CAP, ${ }^{34}$ MRSA may be an important emerging respiratory pathogen in the community, associated with severe necrotizing infection especially following recent influenza. ${ }^{35}$

\section{Pathogenesis}

Inhalation, aspiration and hematogenous spread are the three main mechanisms by which bacteria reach the lungs. The primary route by which organisms enter the lower airways is the aspiration of oropharyngeal secretions into the trachea. Among factors that predispose the elderly to pneumonia are oro-pharyngeal colonization and inadvertent aspiration. Oro-pharyngeal colonization by gram-negative bacilli - is common in patients hospitalized in critical condition. Predisposing factors are poor oral hygiene, abnormal swallowing, increased adhesiveness of gram-negative bacilli mucosal cells, debilitation due to heart disease, respiratory or neoplastic, the reduction of walking and taking a broad-antibiotics spectrum. The aspiration of oro-pharyngeal secretions is increased in patients treated with sedative or narcotic drugs, to cerebrovascular diseases, nasogastric intubation, and esophageal disorders. ${ }^{19}$

Aspiration pneumonia acquired in the community, the usual pathogens are anaerobic bacteria that normally reside in the gingival sulcus (e.g., Peptostreptococci, fusobacterium, anaerobic melanogenic). In nosocomial aspiration pneumonia, the usual pathogens are gram-negative bacilli - sometimes in association with anaerobes. Most cases of pneumonia pneumococcal and gram-negative bacilli - probably follow the micro-suction, in which an inoculum of bacteria small enough propagates from the posterior pharynx to the lungs. The aspiration of larger volumes leads to the spread of 
a relatively large inoculum of oropharyngeal bacteria into the lower airways and occurs in the presence of conditions that affect the state of consciousness or causing dysphagia. $^{36}$

\section{Therapy in the elderly population: general considerations}

The treatment of pneumonia in the elderly includes antimicrobial drug therapy, respiratory support therapy, the adoption of other measures to support and drainage of empyema and pleural effusions of clinical significance, that is, those determinants atelectasis, severe desaturation and worsening dyspnea. Empirical antibiotic therapy, especially in the elderly patient with HAP and VAP, should be preferred. ${ }^{37}$ In VAP the treatment must start within 24 hours from diagnosis and modified depending on clinical response and then were available to microbiological evaluation. The therapy continued for seven days it is effective on the greatest pathogenic agents, more prolonged antibiotic therapy cycles increase the risk of occurrence of resistant organisms. ${ }^{37}$ In 2001 were acknowledged the Tarragona strategy to treat VAP. Main points are: therapy should be started without delay. The choice of antibiotic should be based on the regimen that each patient has received previously. The antibiotic choice can be targeted based on direct stains. The antibiotic regimen should be modified based on microbiological findings. Patients with COPD or 1 week of ventilation should receive combination therapy. ${ }^{37}$ Methicillin-susceptible $S$. aureus (MSSA) should be strongly suspected if Glasgow coma scale (GCS) $<8$. MRSA is not expected in the absence of prior antibiotic administration. ${ }^{37}$ Vancomycin administration for MRSA VAP is associated with very poor outcome. Antifungal therapy is not required even in the presence of Candida sp. colonization. Prolonging antibiotic treatment does not prevent recurrences. Guidelines should be regularly updated and customized to local patterns. ${ }^{37}$

In an elderly patient judicious use of fluids (water balance), nutritional support and a careful management of ventilator support contributes to a better result in patients with HAP and HAP. The recommendations for administration of antimicrobial drugs depend on by the specific agent. They are similar between the different age groups, although the elderly requires a narrower therapeutic monitoring. The potentially nephrotoxic drugs, particularly aminoglycosides, require a regular serum monitoring with frequent assessment of renal function [estimated glomerular filtration rate (eGFR) and creatinine] and this is of great importance especially in frail sarcopenic patients. ${ }^{38}$ Since the elderly often have a compromised cardiac function, fluids and electrolytes intravenously should be administered with caution, considering the water balance, the change in body weight and the state of repletion measurable by ultrasound evaluation of the caval diameter. ${ }^{39}$

Another event to assess in the elderly is secondary diarrhea in antibiotic-associated colitis, which is common if you are using ampicillin, cephalosporins or clindamycin. Are to be considered with particular attention the possible interaction between antimicrobials and other drugs (warfarin) commonly used for the treatment of the elderly and make the monitoring of parameters such as the INR more frequently, sedatives that inhibit deep breath and cough should be not utilized.

\section{Antibiotic therapy in community- acquired pneumonia}

The IDSA/ATS guidelines recommend initiating empirical antimicrobial therapy for all hospitalized patients with a regimen that covers the most common typical as well as atypical pathogens. The guidelines cite several studies that include a substantial proportion of elderly patients. ${ }^{40,41}$

The antibiotic treatment is based on empiric therapeutic regimens for outpatients with or without comorbidities, and for intensive care unit (ICU) and non-ICU patients, and penicillin-allergic patients (Table $\left.2^{26}\right) .{ }^{42}$

Infections due to the majority of CAP

Table 2. Antibiotic treatment for community acquired pneumonia: from 2007 IDSA/ATS Guidelines.

\begin{tabular}{lll} 
Health without comorbidity & \multicolumn{1}{c}{ Outpatient treatment } & \\
Macrolide & With comorbidity & Special concerns \\
$\begin{array}{l}\text { azithromycin } \\
\text { clarithromycin }\end{array}$ & Respiratory fluoroquinolone: & In regions with a high rate $(>25 \%)$ of infection with \\
erythromycin & moxifloxacin & high-level (MIC, $\geq 16 \mu \mathrm{g} / \mathrm{mL})$ macrolide-resistant \\
& gemifloxacin & S. pneumonia, consider the use of alternative agents \\
levofloxacin $[750 \mathrm{mg}]$ & (ceftriaxone, cefpodoxime, cefuroxime) including those \\
& & without comorbidities
\end{tabular}

\begin{tabular}{|c|c|c|}
\hline Strong recommendation; level I evidence & Strong recommendation; level I evidence & Moderate recommendation; level III evidence \\
\hline Doxycycline & $\beta$-lactam plus a macrolide & \\
\hline \multirow[t]{5}{*}{ Weak recommendation; level III evidence } & Strong recommendation; level I evidence & \\
\hline & High-dose amoxicillin [1 g x3] & \\
\hline & Amoxicillin-clavulanate [2 $\mathrm{g}$ x2] & \\
\hline & $\begin{array}{l}\text { Alternatives: } \\
\text { ceftriaxone } \\
\text { cefpodoxime } \\
\text { cefuroxime [ } 500 \mathrm{mg} 2 \text { times daily]; } \\
\text { doxycycline as alternative to the macrolide }\end{array}$ & \\
\hline & Level II evidence & \\
\hline
\end{tabular}

Modified from Mandell et al., $2007 .{ }^{26}$ Comorbidity=chronic heart, lung, liver, or renal disease; diabetes mellitus; alcoholism; malignancies; asplenia; immunosuppressing conditions or use of immunosuppressing drugs; use of antimicrobials within the previous 3 months (in which case an alternative from a different class should be selected); or other risks for DRSP infection. 
pathogens will be adequately treated by use of the recommended empirical regimens for outpatients without comorbidity (azithromycin $500 \mathrm{mg}$ PO one dose, then 250 mg PO daily for $4 \mathrm{~d}$ or clarithromycin 500 mg PO bid or extended-release $1000 \mathrm{mg}$ PO q24h or doxycycline $100 \mathrm{mg}$ PO bid). If received a prior antibiotic within three months: azithromycin or clarithromycin plus amoxicillin $1 \mathrm{~g}$ PO q8h or amoxicillinclavulanate 2 g PO q12h or respiratory fluoroquinolone (e.g., levofloxacin $750 \mathrm{mg}$ PO daily or moxifloxacin $400 \mathrm{mg}$ PO daily). When comorbidities are present (e.g., alcoholism, bronchiectasis/cystic fibrosis, COPD, IV drug user, post influenza, asplenia, diabetes mellitus, lung/liver/renal diseases): levofloxacin $750 \mathrm{mg}$ PO q24h or moxifloxacin $400 \mathrm{mg}$ PO q24h or combination of a beta-lactam (amoxicillin $1 \mathrm{~g}$ PO q8h or amoxicillin-clavulanate $2 \mathrm{~g}$ PO q12h or ceftriaxone $1 \mathrm{~g} \mathrm{IV} / \mathrm{IM} \mathrm{q} 24 \mathrm{~h}$ or cefuroxime $500 \mathrm{mg}$ PO BID) plus a macrolide (azithromycin or clarithromycin) are to be used. Duration of therapy: minimum of 5 days, should be afebrile for 48-72 h, or until afebrile for three days; longer duration of therapy may be needed if initial therapy was not active against the identified pathogen or if it was complicated by extrapulmonary infections. ${ }^{26}$

The emergence of MRSA as a CAP pathogen and the small but significant incidence of CAP due to $P$. aeruginosa are the exceptions. These pathogens occur in specific epidemiologic patterns and with certain clinical presentations, for which empirical antibiotic coverage may be warranted..$^{42}$ A respiratory fluoroquinolone should be used for penicillin-allergic patients.

Data from the CAPO International Cohort Study conducted on 1649 patients with CAP, aged 65 years or older, 975 patients were given antimicrobial regimens adherent to the IDSA/ATS for CAP guidelines, while 660 patients were treated with non-adherent regimens define whether elderly patients hospitalized with CAP had better outcomes if they were treated with empirical antimicrobial therapy adherent to the 2007 IDSA/ATS guidelines for CAP, demonstrated that implementation of national guidelines at the local hospital level has improved not only mortality and length of stay of elderly patients hospitalized with CAP but also time to clinical stability. ${ }^{43}$

\section{Antibiotic therapy in hospital- acquired pneumonia}

Antibiotic therapy differs for Intensive Care Unit (ICU) and non-ICU Inpatient. For non ICU patients [levofloxacin $750 \mathrm{mg}$ IV or PO q24h or moxifloxacin $400 \mathrm{mg}$ IV or PO q24h or combination of a beta-lactam (ceftriaxone $1 \mathrm{~g}$ IV q24h or cefotaxime $1 \mathrm{~g}$ IV q8h or ertapenem $1 \mathrm{~g}$ IV daily or ceftaroline $600 \mathrm{mg}$ IV q12h) plus azithromycin $500 \mathrm{mg}$ IV q24h]. Duration of therapy: minimum of 5 days, should be afebrile for 48$72 \mathrm{~h}$, stable blood pressure, adequate oral intake, and room air oxygen saturation of greater than $90 \%$; longer duration may be needed in some cases.

For ICU inpatient with severe COPD: levofloxacin $750 \mathrm{mg}$ IV or PO q24h or moxifloxacin $400 \mathrm{mg}$ IV or PO q24h or ceftriaxone $1 \mathrm{~g}$ IV q24h or ertapenem $1 \mathrm{~g}$ IV q24h plus azithromycin $500 \mathrm{mg}$ IV q24h If gramnegative rod pneumonia (Pseudomonas) suspected, due to alcoholism with necrotizing pneumoniae, chronic bronchiectasis/tracheobronchitis due to cystic fibrosis, mechanical ventilation, febrile neutropenia with pulmonary infiltrate, septic shock with organ failure: piperacillin-tazobactam $4.5 \mathrm{~g}$ IV q6h or $3.375 \mathrm{~g}$ IV q4h or 4-h infusion of $3.375 \mathrm{~g} \mathrm{q} 8 \mathrm{~h}$ or cefepime $2 \mathrm{~g}$ IV q12h or imipenem/cilastatin $500 \mathrm{mg}$ IV q6h or meropenem $1 \mathrm{~g}$ IV q8h or If penicillin allergic, substitute aztreonam $2 \mathrm{~g}$ IV q6h plus levofloxacin $750 \mathrm{mg}$ IV q24h or moxifloxacin $400 \mathrm{mg}$ IV or PO q24h or aminoglycoside (gentamicin $7 \mathrm{mg} / \mathrm{kg}$ /day IV or tobramycin $7 \mathrm{mg} / \mathrm{kg} /$ day IV). Add azithromycin $500 \mathrm{mg}$ IV q24h if respiratory fluoroquinolone not used. Duration of therapy: 10-14 days.

For ICU inpatient if concomitant with or post influenza: Vancomycin $15 \mathrm{mg} / \mathrm{kg} \mathrm{IV}$ q12h or linezolid $600 \mathrm{mg}$ IV bid plus levofloxacin $750 \mathrm{mg}$ IV q24h or moxifloxacin $400 \mathrm{mg}$ IV or PO q24h. If received prior antibiotic within 3 months: high-dose ampicillin $2 \mathrm{~g}$ IV q6h (or penicillin $\mathrm{G}$, if not resistant); if penicillin allergic, substitute with vancomycin $1 \mathrm{~g}$ IV q12h plus azithromycin $500 \mathrm{mg}$ IV q24h plus levofloxacin $750 \mathrm{mg}$ IV q24h or moxifloxacin $400 \mathrm{mg}$ IV/PO q24h (Table 3). ${ }^{26,44}$

\section{Antibiotic resistance}

Antimicrobial resistance is resistance of a microorganism to an antimicrobial drug that was originally effective for treatment of infections caused by it. CDC define antibiotic resistant microorganisms (for more bacteria) those resistant to one or more classes of antimicrobial agents - often resistant to all available antimicrobials. ${ }^{45}$ Currently, the phenomenon is highly present in elderly people hospitalized and varies depending on the hospital setting and region. The microorganisms that are identified as antibiotic-resistant are: MRSA, Gram-negative extended-spectrum beta-lactamases (ESBL), vancomycin-resistant Enterococcus sp. (VRE), P. aeruginosa multidrug resistant Acinetobacter baumannii and K. pneumonia carbapenemases. A recent article shows that the antibiotic resistance profile to $P$. aeruginos $a$ in the last 10 years has radically changed, and extremely widespread. In fact, on a sample of 168 older patients $(54.2 \%)$ with CAP and (45.8\%) with HAP, $24.4 \%$ had MDR $P$. aeruginosa pneumonia: of which $65.9 \%$ was in nosocomial development, while $34.1 \%$ were community acquired. The resistance to antibiotics was very high especially of the MDR forms developed in the hospital. P. aeruginosa and the MDR form showed a high resistance to ciprofloxacin $(\mathrm{CAP}=35.2 \%$ vs $\mathrm{HAP}=24.0 \%$; $\mathrm{CAP}=61.5 \%$ vs $\mathrm{HAP}=70.4 \%)$, levofloxacin $(\mathrm{CAP}=34$, $6 \%$ vs $\mathrm{HAP}=24.5 \%$; $\mathrm{CAP}=66.7 \%$ against $\mathrm{HAP}=64.3 \%)$, ceftazidime $(\mathrm{CAP}=15.9 \% v \mathrm{~s}$ $\mathrm{HAP}=30.9$; $\mathrm{CAP}=33.3 \%$ vs $\mathrm{HAP}=61.5 \%$ ), piperacillin $(\mathrm{CAP}=24.2 \%$ vs $\mathrm{HAP}=29.9 \%$; $\mathrm{CAP}=44.4 \%$ against $\mathrm{HAP}=57.1 \%$ ), imipenem $\quad(\mathrm{CAP}=28.6 \% \quad$ vs $\mathrm{HAP}=27, \quad 3 \%$; $\mathrm{CAP}=55.6 \% \quad$ against $\mathrm{HAP}=50.0 \%)$, piperacillin and tazobactam $(\mathrm{CAP}=23.1 \%$ vs $\mathrm{HAP}=28.6 \% ; \quad \mathrm{CAP}=44.4 \%$ against $\mathrm{HAP}=50.0 \%)$, tobramycin $(\mathrm{CAP}=\mathrm{HAP}=$ $28.0 \%$ vs $17.2 \%$; $\mathrm{CAP}=52.0 \%$ against $\mathrm{HAP}=27.3 \%)$, gentamicin $(\mathrm{CAP}=26.4 \%$ vs $\mathrm{HAP}=18.2 \%$; CAP HAP $=44.4 \%$ vs $21.4 \%$ ), and meropenem $\quad(\mathrm{CAP}=20.2 \% \quad$ vs $\mathrm{HAP}=20.3 \% ; \quad \mathrm{CAP}=42.3 \% \quad$ against $\mathrm{HAP}=50.0 \%$ ). A high of $P$. aeruginosa resistance and MDR $P$. aeruginosa was found cefepime $(\mathrm{CAP}=11.1 \%$ vs $\mathrm{HAP}=$ $23.3 \%$; $\mathrm{CAP}=25.9 \%$ vs $\mathrm{HAP}=50.0 \%$ ), and amikacin $(\mathrm{CAP}=10.2 \%$ vs $\mathrm{HAP}=9.1 \%$; $\mathrm{CAP}=9.1 \%$ vs $\mathrm{HAP}=27.3 \%$ ). No pathogens were resistant to colistin. ${ }^{46}$ In our experience at the Maugeri Foundation - Institute of Rehabilitation of Telese Terme, the prevalence of antibiotic resistance appears to be very high, considering that of 1413 microbiological tests $718(50.8 \%)$ isolates MDR bacteria, with a high detection of ESBL microorganisms, MRSA, A. baumani and carbapenem-resistant $K$. pneumoniae (CRKP) (Figure 2) these data are an expression of the difficulties found in the clinical management of pneumonia in frail patients acquired both in the community and in hospitals considering the high prevalence of pneumonia even in communities. MDR Pseudomonas resistant to most common antibiotics (ciprofloxacin, levofloxacin) and with moderate sensitivity profile for the third cephalosporins (ceftazidime) and fourth generation (cefepime); carbapenems (imipenem and meropenem). Antibacterial 
penicillin (ampicillin + tazobactam) more active drugs but at the sole hospital prescription or aminoglycoside (tobramycin, gentamicin and amikacin), specific but less tolerated by the elderly population due to the side effects.

\section{4}

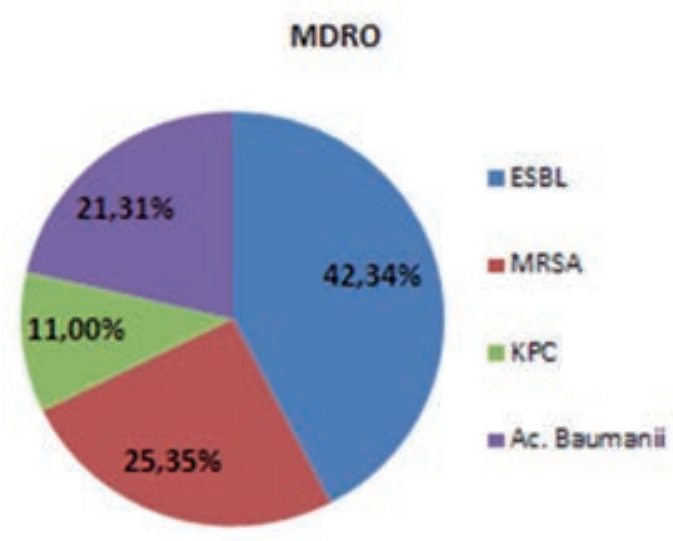

In order to evaluate the risk of multidrug resistant pathogens in patients with pneumonia could be used scoring systems such as that developed by Shorr, with a score from 0 to 10 where more than 5 points evidenced a prevalence of $\mathrm{MDR}>75 \%{ }^{47}$ and Aliberti with a score from 0 to 12.5 where $\geq 3$ points identified an MDR prevalence of $38.0 \%{ }^{48}$ (Table 4$)$.

\begin{tabular}{|l|l|}
\hline Total MDRO & 718 \\
\hline ESBL & 304 \\
\hline MRSA & 182 \\
\hline KPC & 79 \\
\hline AC. Baumanii & 153 \\
\hline
\end{tabular}

Figure 2. Multi-drug resistant organisms (MDRO) - Maugeri Foundation, Institute of Rehabilitation of Telese Terme (BN), Italy.

\section{Pneumonia in Intensive Care Unit}

Data from ECDC on 110,945 patients admitted to an intensive care unit for more than two days demonstrate an incidence of pneumonia of $5.3 \%$ and $92 \%$ of cases is associated with intubation. Average incidence for intensive care was 6.4 episodes per 1000 patient-days with a range from 2.2 to intensive care units with less than $30 \%$ of patients intubated with 5.7 in the intensive care unit with $30-59 \%$ of intubated patients,

Table 3. Antibiotic treatment for community acquired pneumonia: from 2007 and 2016 IDSA/ATS Guidelines.

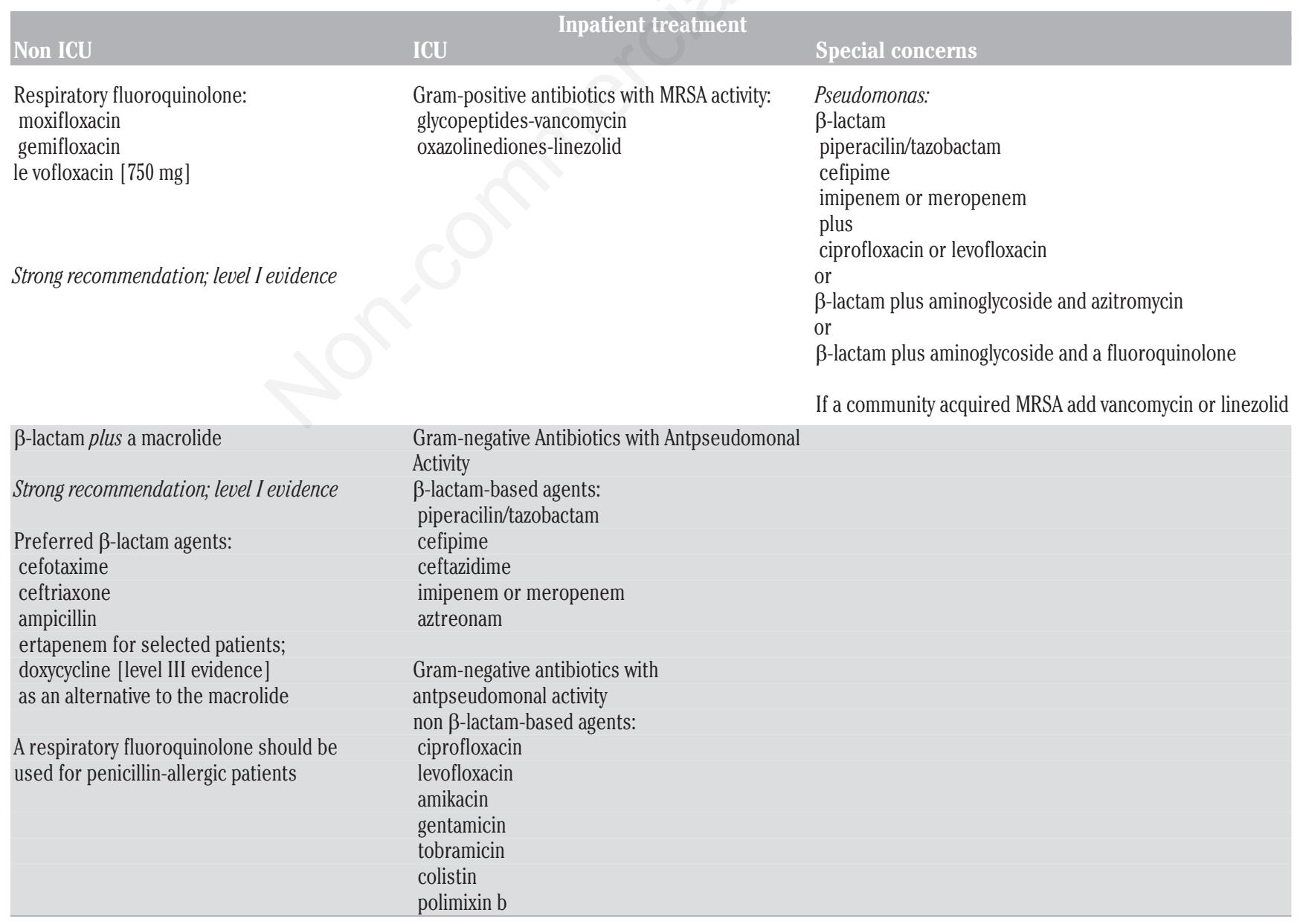

Modified from Mandell et al., $2007^{26}$ and Kalil et al., 2016. ${ }^{44}$ 
Table 4. Scoring systems to assess the multi-drug resistant pathogens in patients with pneumonia.

\begin{tabular}{|c|c|c|c|}
\hline $\begin{array}{l}\text { Shorr } \\
\text { Score }\end{array}$ & Variable & \multicolumn{2}{|c|}{ Aliberti } \\
\hline 1 & Admitted to ICU within $24 \mathrm{~h}$ from admission & $\begin{array}{l}0 \\
0.5\end{array}$ & $\begin{array}{l}\text { No risk factors for MDR pathogens } \\
\geq 1 \text { of the following: CVD, diabetes, COPD, antimicrobial treatment in the prior } 90 \\
\text { days, immunosuppression, home wound care or IV therapy }\end{array}$ \\
\hline 2 & \multicolumn{3}{|l|}{ Chronic hemodialysis } \\
\hline 3 & Long-term facility resident & 3 & Long-term facility resident \\
\hline 4 & Hospitalization in the prior 90 days & $\begin{array}{l}4 \\
5\end{array}$ & $\begin{array}{l}\text { Hospitalization in the prior } 90 \text { days } \\
\text { Chronic renal failure }\end{array}$ \\
\hline \multicolumn{2}{|c|}{ Maximum score 10} & \multicolumn{2}{|c|}{ Maximum score 12.5} \\
\hline$<3$ & $20 \%$ & $<0.5$ & $8 \%$ \\
\hline $3-5$ & $55 \%$ & $\geq 338 \%$ & \\
\hline$>5$ & $75 \%$ & & \\
\hline
\end{tabular}

up to 7.8 in the intensive care unit with $\geq 60 \%$ of intubated patients overall, the most frequently isolated microorganisms in pneumonia acquired in the ICU were $P$. aeruginosa, $S$. aureus (with an average percentage of isolated MRSA of $43.0 \%$ ), Klebsiella spp., In Italy, the Acinetobacter sp. and Klebsiella sp. are the most commonly isolated in ICU pneumonia compared to other European countries. ${ }^{49}$

\section{The ventilatory support therapy}

Non-invasive ventilation (NIV) is used in acute respiratory failure due to pneumonia. ${ }^{50}$ Nava et al. in a randomized controlled study in elderly patients ( $>75$ years) with acute hypercapnic respiratory failure it has shown that NIV reduces the need for intubation and the mortality rate by improving arterial blood gasses and dyspnea, suggesting the NIV as an alternative treatment for elderly patients at high risk for intubation. ${ }^{51}$ In elderly patients in end-stage pneumonia often is the precipitating event that leads to death. In this scenario, palliative care is usually the treatment of choice and one of the main issues to be addressed is the worsening of dyspnea. In a recent study, Nava et al. has shown that NIV is more effective than oxygen-therapy in reducing dyspnea in this patient group, so the NIV could play a role in the treatment of moderate to severe acute respiratory caused by pneumonia, in patients receiving palliative care or for patients with a state of do not intubate (DNI). ${ }^{52}$

\section{Aspects of terminal patients}

In the elderly, pneumonia is often the terminal event of different comorbidities, such as diabetes mellitus, COPD, heart failure, malignancies, and dementia. Elderly patients suffering from other diseases are more likely to run into complications, e.g., adult respiratory distress syndrome, empyema and septic shock. Pneumonia in older individuals without terminal disease has to be distinguished from end-of-life pneumonia. In the latter setting, the attributable mortality of pneumonia is low, and antibiotics have little effect on life expectancy and should be used only if they provide the best means to alleviate suffering. ${ }^{53}$

\section{Conclusions}

The 2015 British Thoracic Society Adult Community Acquired Pneumonia Audit Report ${ }^{54}$ stressed the message that in light of the aging population, with more at-risk individuals, it is important that efforts are taken to describe current care processes so that strategies to improve care can be appropriately targeted and implemented to the elderly.

One of the targets that should be reached is to overcome the initial inadequate therapy in critically ill patients with serious infections, particularly in frail elderly. Initial appropriate therapy means starting with a broad-spectrum antibiotic and then focusing on an antibiotic treatment based on microbiological results. Broad-spectrum antibiotics should not be held in reserve. Should be based on patient stratification, considering local epidemiology. Of great importance in the elderly patient is not only the use of the appropriate drug, but also, the correct dose, and duration. The Myth that there is time to start with one therapy and then escalate later should be avoided in the elderly, where inadequate initial antimicrobial therapy increases mortality. ${ }^{55-57}$

Even more attention in the light of aging phenomenon must be posed as a measure of prevention such as smoking cessation and vaccination. The influenza vaccination and pneumococcal are effective measures for the prevention of pneumonia in the elderly.

The World Health Organization (WHO) identifies the $75 \%$ vaccination coverage the minimum coverage target for the ultra-65year-old population. Last year in Italy we vaccinated only $48.6 \%$ of our elders. ${ }^{58}$

\section{References}

1. Osler W. The principles and practice of medicine. 9th. New York and London: D. Appleton and Co.; 1920.

2. National Institute for Health and Care Excellence (NICE). Pneumonia in adults: diagnosis and management. Clinical guidelines [CG191] Published date: December 2014. Available from: https://www.nice.org. uk/guidance/cg191

3. Sahyoun NR, Lentzner H, Hoyert D, Robinson KN. Trends in causes of 
deaths among the elderly. Centers for Disease Control and Prevention (CDC); March 2001. Available from: http:// www.cdc.gov/nchs/data/ahcd/agingtren ds/01death.pdf

4. Janssens JP, Krause KH. Pneumonia in the very old. Lancet Infect Dis 2004; 4:112-24.

5. Jackson ML, Neuzil KM, Thompson WW, et al. The burden of communityacquired pneumonia in seniors: results of a population-based study. The burden of community-acquired pneumonia in seniors: results of a population-based study. Clin Infect Dis 2004;39:1642-50.

6. Valley TS, Sjoding MW, Ryan AM, et al. Association of intensive care unit admission with mortality among older patients with pneumonia. JAMA. 2015;314:1272-9.

7. European Centre for Disease Prevention and Control (ECDC). Annual epidemiological report 2014. Antimicrobial resistance and healthcare-associated infections. Annual epidemiological report 2014. Antimicrobial resistance and healthcare-associated infections. Stockholm: ECDC; 2015.

8. Dwyer LL, Harris-Kojetin LD, Valverde $\mathrm{RH}$, et al. Infections in long-term care populations in the United States. J Am Geriatr Soc 2013;61:341-9.

9. Finkelstein MS, Petkun WM, Freedman ML, Antopol SC. Pneumococcal bacteremia in adults: age-dependent differences in presentation and in outcome. $\mathrm{J}$ Am Geriatr Soc 1983;31:19-27.

10. Faverio P, Aliberti S, Bellelli G, et al. The management of communityacquired pneumonia in the elderly. Eur J Intern Med 2014;25:312-9.

11. Mehr DR, Binder EF, Kruse RL, et al. Clinical findings associated with radiographic pneumonia in nursing home residents. J Fam Pract 2001;50:931-7.

12. Hoare Z, Lim WS. Pneumonia: update on diagnosis and management. BMJ 2006;332:1077-9.

13. Kaye KS, Stalam M, Shershen WE, Kaye D. Utility of pulse oximetry in diagnosing pneumonia in nursing home residents. Utility of pulse oximetry in diagnosing pneumonia in nursing home residents. Am J Med Sci 2002;324:237-42.

14. Russo A, Falcone M, Venditti M. Early identification of severe communityonset pneumonia in frail elderly patient. Intern Emerg Med 2014;9:119-20.

15. Franquet T. Imaging of pneumonia: trends and algorithms. Eur Respir J 2001:18:196-208.

16. Blaivas M. Lung ultrasound in evaluation of pneumonia. J Ultrasound Med 2012;31:823-6.
17. Ye X, Xiao H, Chen B, Zhang S. Accuracy of lung ultrasonography versus chest radiography for the diagnosis of adult community-acquired pneumonia: review of the literature and metaanalysis. PLoS One 2015;10:e0130066.

18. Klapdor B, Ewig S, Pletz MW, et al. Community-acquired pneumonia in younger patients is an entity on its own. Eur Respir J 2012;39:1156-61.

19. Ferrara N, Fuschillo S, Corbi G, et al. [Pneumonia in the elderly]. G Gerontol 2005;LIII:594-602. [In Italian].

20. Fine MJ, Auble TE, Yealy DM, et al. A prediction rule to identify low-risk patients with community-acquired pneumonia. N Engl J Med 1997;336: 243-50.

21. Aujesky D, Fine MJ. The pneumonia severity index: a decade after the initial derivation and validation. Clin Infect Dis 2008;47:S133-9.

22. Lim WS, van der Eerden MM, Laing R, et al. Defining community acquired pneumonia severity on presentation to hospital: an international derivation and validation study. Thorax 2003;58:377-82.

23. Heppner HJ, Sehlhoff B, Niklaus D, et al. Pneumonia severity index (PSI), CURB-65, and mortality in hospitalized elderly patients with aspiration pneumonia. Z Gerontol Geriatr 2011;44:229-34.

24. Serisier DJ, Williams S, Bowler SD. Australasian respiratory and emergency physicians do not use the pneumonia severity index in community-acquired pneumonia. Respirology 2013;18:291-6.

25. Aliberti S, Faverio P, Blasi F. Hospital admission decision for patients with community-acquired pneumonia. Curr Infect Dis Rep 2013;15:167-76.

26. Mandell LA, Wunderink RG, Anzueto A, et al. Infectious Diseases Society of America/American Thoracic Society consensus guidelines on the management of community-acquired pneumonia in adults. Clin Infect Dis 2007;44:S27-72.

27. Niederman MS. Making sense of scoring systems in community acquired pneumonia. Respirology 2009;14:327.

28. Galizia G, Cacciatore F, Testa G, et al. Role of clinical frailty on long-term mortality of elderly subjects with and without chronic obstructive pulmonary disease. Aging Clin Exp Res 2011;23:118-25.

29. Pilotto A, Addante F, Ferrucci L, et al. The multidimensional prognostic index predicts short- and long-term mortality in hospitalized geriatric patients with pneumonia. J Gerontol A Biol Sci Med 2009;64A:880-7.

30. Pilotto A, Dini S, Daragjati J, et al.
Combined use of the multidimensional prognostic index (MPI) and procalcitonin serum levels in predicting 1month mortality risk in older patients hospitalized with community-acquired pneumonia (CAP): a prospective study. Aging Clin Exp Res 2017 [Epub ahead of print].

31. Niederman MS, Mandell LA, Anzueto A, et al. Guidelines for the management of adults with community-acquired pneumonia. Diagnosis, assessment of severity, antimicrobial therapy, and prevention. Am J Respir Crit Care Med 2001;163:1730-54.

32. Jain S, Self WH, Wunderink RG, et al. Community-acquired pneumonia requiring hospitalization among U.S. Adults. N Engl J Med 2015;373:415-27.

33. Tadros M, Williams V, Coleman BL, et al. Epidemiology and outcome of pneumonia caused by methicillin-resistant Staphylococcus aureus (MRSA) in Canadian hospitals. PLoS One 2013;8:e75171.

34. Moran GJ, Krishnadasan A, Gorwitz RJ, et al. Prevalence of methicillinresistant Staphylococcus aureus as an etiology of community-acquired pneumonia. Clin Infect Dis 2012;54:112633.

35. Kallen AJ, Brunkard J, Moore Z, et al. Staphylococcus aureus communityacquired pneumonia during the 2006 to 2007 influenza season. J Ann Emerg Med 2009;53:358-65.

36. Marik PE. Aspiration pneumonitis and aspiration pneumonia. N Engl J Med 2001;344:665-71.

37. Bodí M, Ardanuy C, Olona M, et al. Therapy of ventilator-associated pneumonia: the Tarragona strategy. Clin Microbiol Infect 2001;7:32-3.

38. Sharma D, Hawkins M, Abramowitz MK. Association of sarcopenia with eGFR and misclassification of obesity in adults with CKD in the United States. Clin J Am Soc Nephrol 2014;9:2079-88.

39. Pellicori P, Carubelli V, Zhang J, et al. IVC diameter in patients with chronic heart failure: relationships and prognostic significance. JACC Cardiovasc Imaging 2013;6:16-28.

40. Ruiz M, Ewig S, Marcos MA, et al. Etiology of community-acquired pneumonia: impact of age, comorbidity, and severity. Am J Respir Crit Care Med 1999;160:397-405.

41. Gleason PP, Meehan TP, Fine JM, et al. Associations between initial antimicrobial therapy and medical outcomes for hospitalized elderly patients with pneumonia. Arch Intern Med 1999;159: 2562-72. 
42. Mandell LA, Wunderink RG, Anzueto A, et al. Infectious Diseases Society of America/American Thoracic Society consensus guidelines on the management of community-acquired pneumonia in adults. Clin Infect Dis 2007;44 :S27-72.

43. Arnold FW, LaJoie AS, Brock GN, et al. Improving outcomes in elderly patients with community-acquired pneumonia by adhering to national guidelines: Community-Acquired Pneumonia Organization International cohort study results. Arch Intern Med 2009;169: 1515-24.

44. Kalil AC, Metersky ML, Klompas M, et al. Management of Adults With Hospital-acquired and Ventilator-associated Pneumonia: 2016 Clinical Practice Guidelines by the Infectious Diseases Society of America and the American Thoracic Society. Clin Infect Dis 2016;63:1-51.

45. Siegel F. Management of multidrugresistant organisms in healthcare settings, 2006. Am J Infect Control 2007; 35:S165-93.

46. Yayan J, Ghebremedhin B, Rasche K. Antibiotic resistance of Pseudomonas aeruginosa in Pneumonia at a single University Hospital Center in Germany over a 10-Year Period. PLoS One 2015; 10:e0139836.

47. Shorr AF, Myers DE, Huang DB, et al. A risk score for identifying methicillin- resistant Staphylococcus aureus in patients presenting to the hospital with pneumonia. BMC Infect Dis 2013;13: 268.

48. Aliberti S, Cilloniz C, Chalmers JD, et al. Multidrug-resistant pathogens in hospitalised patients coming from the community with pneumonia: a European perspective. Thorax 2013;68: 997-9.

49. European Centre for Disease Prevention and Control (ECDC). Annual epidemiological report 2014. Antimicrobial resistance and healthcare-associated infections. Stockholm: ECDC; 2015.

50. Carrillo A, Gonzalez-Diaz G, Ferrer M, et al. Non-invasive ventilation in community-acquired pneumonia and severe acute respiratory failure. Intensive Care Med 2012;38:458-66.

51. Nava S, Grassi M, Fanfulla F, et al. Non-invasive ventilation in elderly patients with acute hypercapnic respiratory failure: a randomised controlled trial. Age Ageing 2011;40:444-50.

52. Nava S, Ferrer M, Esquinas A, et al. Palliative use of non-invasive ventilation in end-of-life patients with solid tumours: a randomised feasibility trial. Lancet Oncol 2013;14:219-27.

53. Janssens J, Krause KH. Pneumonia in the very old. Lancet Infect Dis 2004;4: 112-24.

54. Daniel P, Bewick T, Welham S, Lim
WS. Adult Community Acquired Pneumonia (CAP) Audit Report National Audit Period: 1 December 2014 - 31 January 2015. London: British Thoracic Society; 30 November 2015. Available from: https://www.britthoracic.org.uk/document-library/auditand-quality-improvement/auditreports/bts-adult-community-acquiredpneumonia-audit-report-2014-15

55. Kollef MH, Sherman G, Ward S, Fraser VJ. Inadequate antimicrobial treatment of infections: a risk factor for hospital mortality among critically ill patients. Chest 1999;115:462-74.

56. Ibrahim EH, Sherman G, Ward S, et al. The influence of inadequate antimicrobial treatment of bloodstream infections on patient outcomes in the ICU setting. Chest 2000;118:146-55.

57. Iregui M, Ward S, Sherman G, et al. Clinical importance of delays in the initiation of appropriate antibiotic treatment for ventilator-associated pneumonia. Chest 2002;122:262-8.

58. InfluNet - Istituto Superiore di Sanità (ISS). Rapporto epidemiologico Stagione Influenzale 2015-2016. Settimana 2015-48 dal 23 al 29 Novembre 2015. Roma: InfluNet - ISS; Rapporto N. 6 del 2 Dicembre 2015. Available from: http://www.iss.it/binary/iflu/cont/Influnet_2015_48.pdf 